\title{
Factors influencing the aggregation behavior of residual associative polymer in produced oily fluids
}

\author{
Shi-Jia Chen ${ }^{1,2} \cdot$ Bin Chen ${ }^{1} \cdot$ Hong-Qing Zhu ${ }^{1} \cdot$ Cheng-Sheng Wang ${ }^{1} \cdot$ \\ Xiao-Yan $\mathrm{Wu}^{1} \cdot$ Peng $\mathrm{Lv}^{1}$
}

Received: 14 July 2016/Published online: 24 December 2016

(c) The Author(s) 2016. This article is published with open access at Springerlink.com

\begin{abstract}
The influence of emulsified oil, suspended solids, $\mathrm{Fe}^{3+}, \mathrm{Fe}^{2+}$, cationic water clarifier and sulfate-reducing (SR) bacteria on the aggregation behavior of residual hydrophobic modified polyacrylamide in treated oily wastewater from polymer flooding was studied by fluorescence spectroscopy and dynamic light scattering. The result of $I_{1} / I_{3}$ showed that the polarity of hydrophobic microdomains increased, whereas the size of the hydrophobic microdomains may be decreased, where the value of $I_{1} / I_{3}$ represents the ratio of the intensity of peak $I_{1}$ $(374.0 \mathrm{~nm})$ to that of peak $I_{3}(385.0 \mathrm{~nm})$ of the vibration fine structure of pyrene monomer emission in residual polymer solution. The results of the ratio of $I_{1}$ at $48 \mathrm{~h}$ to $I_{1}$ at $0 \mathrm{~h}\left(I_{1,48 \mathrm{~h}} / I_{1,0 \mathrm{~h}}\right)$ indicated that oil and cationic water clarifier could inhibit the aggregation to some extent, while $\mathrm{Fe}^{2+}$ and suspended solids were helpful for aggregation, and $\mathrm{Fe}^{3+}$ and SR bacteria had no significant influence on the aggregation of polymer.
\end{abstract}

Keywords Aggregation behavior - Fluorescence spectrum - Residual polymer in treated water . Hydrophobic modified polyacrylamide

Shi-Jia Chen

chenshj2@cnooc.com.cn

1 CNOOC EnerTech-Drilling and Production Co., Tianjin 300452, China

2 State Key Laboratory of Offshore Oilfield Exploitation, Tianjin 300452, China

Edited by Xiu-Qin Zhu

\section{Introduction}

Polymer flooding plays a major role in global crude oil recovery (Wever et al. 2011), and this process can enhance oil recovery by $12 \%$ compared with water flooding (Shen et al. 2005; Xu et al. 2010; Lin et al. 2008). In recent years, polymer flooding has been widely used in major oil fields of China, such as Daqing and Shengli Oilfields (Gao et al. 2011; Shi et al. 2010, 2012; Feng et al. 2009; Zhang and Yue 2008; Zhang et al. 2008). One of the most widely used water-soluble polymers is partially hydrolyzed polyacrylamide (HPAM), which controls mobility in reservoirs by increasing the viscosity of the injected water, and more importantly, by reducing the permeability of the formation ( $\mathrm{Lu}$ et al. 2012; Ren et al. 2006; Guo et al. 2014; Lin et al. 2011). Usually, there is residual polymer in treated oily wastewater produced from polymer flooding (TOWPF) (Yang et al. 2014; Li et al. 2012; Lei et al. 2008). TOWPF can be used for reinjection or polymer flooding (Qu et al. 2014; Liu et al. 2010). In addition, there were many other substances in the TOWPF, such as emulsified oil, suspended solids, $\mathrm{Fe}^{3+}, \mathrm{Fe}^{2+}$, cationic water clarifier and sulfate-reducing (SR) bacteria. These substances have great influence on the stability of residual polymer. If the polymer is not stable, then it might aggregate and sediment in the buffer vessel, thereby affecting the reinjection process. Therefore, it is necessary to investigate the aggregation behavior of residual polymer in water. Currently, a large number of reports are focused on the effect of temperature and concentration of salt on the aggregation behavior in water of the polymer used in polymer flooding (Han et al. 2012; Zhao et al. 2009; Liu et al. 2016; Zhong et al. 2010). However, no report has been found which discusses the effect of emulsified oil, suspended solids, $\mathrm{Fe}^{3+}, \mathrm{Fe}^{2+}$, cationic water clarifier and SR bacteria, on the aggregation behavior of the residual polymer during the treatment 
process of produced water. Generally, dynamic light scattering (DLS) and fluorescent microscopy methods (Liu et al. 2016; Zhong et al. 2010) are most frequently used to study the aggregation behavior of polymers in water. Hence, these two methods were adopted in this paper to systematically investigate the effects of emulsified oil, suspended solids, $\mathrm{Fe}^{3+}, \mathrm{Fe}^{2+}$, cationic water clarifier and SR bacteria on the aggregation behavior of residual polymer. The results should be helpful for analyzing the stability of residual HMPAM in TOWPF.

\section{Experiments}

\subsection{Materials and instruments}

TOWPF was taken from SZ36-1 Oilfield in Bohai Bay in China. In this offshore oil field, the oily wastewater treatment process is shown in Fig. 1.

The oil displacement agent was hydrophobic modified polyacrylamide (HMPAM). Therefore, there was residual HMPAM in the produced wastewater. The produced wastewater containing HMPAM was treated by skimmer, air floatation and walnut shell filter in turn, and TOWPF was obtained (Zhang et al. 2015a, b), and then the TOWPF flowed into the buffer vessel. The quality of TOWPF is listed in Table 1. In general, the TOWPF would stay in the buffer vessel for about 2-48 h. During this period, precipitates containing HMPAM would appear at the bottom of the buffer vessel (Hu et al. 2013; Tuncal and Uslu 2014). This phenomenon indicated that the stability of residual HMPAM in TOWPF was reduced for some reason.

Cationic water clarifier used was provided by the CNOOC EnerTech-Drilling and Production Co. (Tianjin, China). Pyrene was obtained from Aladdin-Reagent Corporation (Shanghai, China).

The fluorescence spectrum was measured with a LS55 fluorescence spectrophotometer (PerkinElmer Corporation, UK).

Dynamic light scattering (DLS) experiments were performed using Brookhaven Instruments 90Plus/BI-MAS (Brookhaven Instruments, NY, USA). Hydrodynamic radius $\left(R_{\mathrm{h}}\right)$ was obtained from the DLS results and calculation according to the CONTIN algorithm.
Size exclusion chromatography (SEC) analysis was conducted at $30{ }^{\circ} \mathrm{C}$ using a Waters 515 liquid chromatograph connected with a Waters 2410 refractive index detector. The gel permeation column was linear ultrahydrogel $\left(7.8 \times 300 \mathrm{~mm}^{2}\right)$, and the solvent used was distilled water. Polymer standards of dextran were used according to National Institute for the Control of Pharmaceutical and Biological Products (NICPBP, China). The polymer samples were dissolved in $0.1 \mathrm{M} \mathrm{NaCl}$ solution and analyzed at a flow rate of $0.8 \mathrm{~mL} \mathrm{~min}{ }^{-1}$. The number average molecular weight $\left(M_{\mathrm{n}}\right)$, weight average molecular weight $\left(M_{\mathrm{w}}\right)$ and polydispersity index (PDI) of the polymer samples were measured by SEC.

Intrinsic viscosities $([\eta])$ of polymers were measured by the "five-spot" dilution method using an Ubbelohde viscometer at $30{ }^{\circ} \mathrm{C}$, where the solvent was $1 \mathrm{M} \mathrm{NaCl}$ solution. Viscosity average molecular weight $\left(M_{\eta}\right)$ was calculated through the following Eq. (1) (Feng 1999):

$[\eta]=4.75 \times 10^{-3} M_{\eta}^{0.80}$

\subsection{Extraction of residual HMPAM in TOWPF}

Firstly, 2 L TOWPF was concentrated to $200 \mathrm{~mL}$. Then, the concentrated TOWPF was purified with an osmotic membrane, with a molecular weight cutoff of 10,000 , for 3 days. At last, after vacuum drying for $8 \mathrm{~h}$ at $60{ }^{\circ} \mathrm{C}$, the HMPAM was obtained. The structure of HMPAM is shown in Fig. 2. The hydrophobic group in HMPAM molecule is long-chain alkane dimethyl allyl ammonium chloride (the number of carbon atoms in the long-chain alkane is more than 12). The mole content of hydrophobic groups in HMPAM is about $1 \%$.

\subsection{Aggregation behavior of residual HMPAM}

\subsubsection{Preparation of residual HMPAM solution containing pyrene}

Firstly, $1 \mathrm{~L}$ HMPAM aqueous solution $(60 \mathrm{mg} / \mathrm{L})$ was prepared by using simulated formation water as solvent (the composition of simulation formation is listed in Table 2). Then, $5 \mathrm{~mL}$ of a solution of $500 \mathrm{mg} / \mathrm{L}$ pyrene in ethanol was added into the HMPAM aqueous solution. At last, the mixture was allowed to heat at $65{ }^{\circ} \mathrm{C}$ for $2 \mathrm{~h}$ to

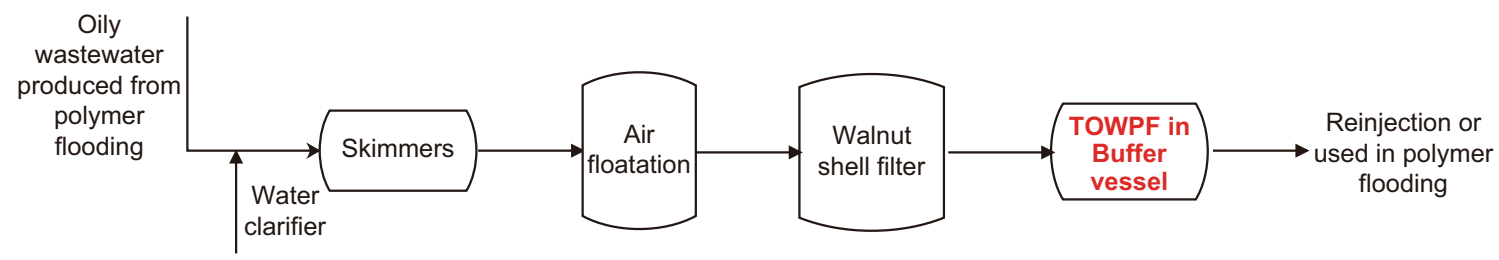

Fig. 1 Oily wastewater treatment process in one offshore oil field in China 
Table 1 Water quality of TOWPF in buffer vessel in Fig. 1

\begin{tabular}{llllll}
\hline $\begin{array}{l}\text { HMPAM } \\
\text { concentration, } \mathrm{mg} / \mathrm{L}\end{array}$ & $\begin{array}{l}\text { Oil content, } \\
\mathrm{mg} / \mathrm{L}\end{array}$ & $\begin{array}{l}\text { Suspended solid } \\
\text { content, } \mathrm{mg} / \mathrm{L}\end{array}$ & $\begin{array}{l}\mathrm{Fe}^{3+}+\mathrm{Fe}^{2+} \\
\text { concentration, } \mathrm{mg} / \mathrm{L}\end{array}$ & $\begin{array}{l}\text { Cationic water clarifier } \\
\text { concentration, mg/L }\end{array}$ & $\begin{array}{l}\mathrm{SR} \text { bacteria, } \\
\mathrm{ind} / \mathrm{mL}\end{array}$ \\
\hline 60 & 30 & 15 & 0.4 & 40 & 110 \\
\hline
\end{tabular}

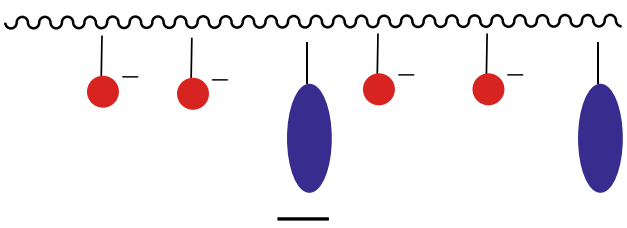

Carboxyl group

Hydrophobic group

mmm Polyacrylamide main chain

Fig. 2 Molecular structure of HMPAM

Table 2 Composition of simulation formation, $\mathrm{mg} / \mathrm{L}$

\begin{tabular}{lllllll}
\hline $\mathrm{NaCl}$ & $\mathrm{KCl}$ & $\mathrm{CaCl}_{2}$ & $\mathrm{MgCl}_{2} \cdot 6 \mathrm{H}_{2} \mathrm{O}$ & $\mathrm{Na}_{2} \mathrm{SO}_{4}$ & $\mathrm{Na}_{2} \mathrm{CO}_{3}$ & $\mathrm{NaHCO}_{3}$ \\
\hline 7341 & 66 & 764.7 & 1327 & 126 & 25 & 429
\end{tabular}

remove the ethanol and HMPAM solution containing pyrene was obtained.

\subsubsection{Mixture of residual HMPAM solution containing pyrene with different substances}

Firstly, the substances which are listed in Table 1, such as oil, suspended solids and $\mathrm{Fe}^{3+}$, were added, respectively, to $800 \mathrm{~mL}$ HMPAM solution containing pyrene (the dosage of substance is given in Table 1).

Then, the mixture was stirred with an emulsifying machine at $7000 \mathrm{r} / \mathrm{min}$ for $15 \mathrm{~min}$. At last, the mixture was distributed into four tubulated bottles (see Fig. 3) for the experiments.

\subsubsection{Fluorescence spectrum and DLS}

Firstly, four tubulated bottles were kept at $65{ }^{\circ} \mathrm{C}$ for 0,8 , 24 and $48 \mathrm{~h}$, respectively. Then, different samples were obtained successively from the bottom of the tubulated bottle. The first $50 \mathrm{~mL}$ was the bottom solution, the intermediate $100 \mathrm{~mL}$ was the middle solution, and the last $50 \mathrm{~mL}$ was the top solution.

The solutions at different layers were filtered by $0.8-\mu \mathrm{m}$ microporous membrane, and then, the aggregation behavior of residual HMPAM was investigated by using the fluorescence spectrum and DLS result.

Because hydrophobic groups in HMPAM were not water-soluble, they would aggregate and hydrophobic

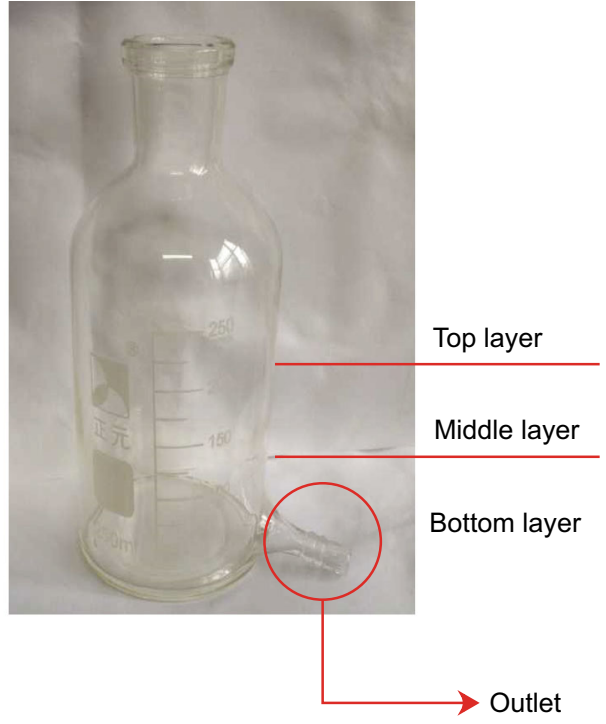

Fig. 3 Picture of tubulated bottle

domains can be formed by hydrophobic groups from one HMPAM molecule or several HMPAM molecules (Zhang et al. 2015a, b; Fang et al. 2014). Pyrene would be soluble in the hydrophobic domain. The vibronic structure of the fluorescence spectrum of the monomeric pyrene is known to be sensitive to the local polarity. In particular, the $I_{1} / I_{3}$ ratio of the intensities of the first and third vibronic peaks increases on going from aliphatic to polar solvents (Aguiar et al. 2003; Kim et al. 2000; Ismail 2008) and can be used as an index of the effective local polarity of the pyrene solubilization site in the hydrophobic domain. The ratio $I_{1} /$ $I_{3}$ is the ratio of the intensity of peak $I_{1}(374.0 \mathrm{~nm})$ to that of peak $I_{3}(385.0 \mathrm{~nm})$ of the vibration fine structure of pyrene monomer emission. In addition, usually, the $I_{1}$ or $I_{3}$ would increase with the number of hydrophobic domains because more pyrene can be soluble in the solution when there were more hydrophobic domains. Therefore, the 
Table 3 Characterizations of residual HMPAM

\begin{tabular}{llll}
\hline$M_{\mathrm{n}}, \mathrm{g} / \mathrm{mol}$ & $M_{\mathrm{w}}, \mathrm{g} / \mathrm{mol}$ & $M_{\eta}, \mathrm{g} / \mathrm{mol}$ & PDI \\
\hline $3.61 \times 10^{5}$ & $1.41 \times 10^{6}$ & $1.00 \times 10^{6}$ & 3.91
\end{tabular}

value of $I_{1}$ can reflect the number of hydrophobic domains at the same experimental condition, whereas the $R_{\mathrm{h}}$ obtained by DLS can reflect the size of HMPAM aggregates.

\section{Results and discussion}

\subsection{Characterization of residual HMPAM}

The characterization of residual HMPAM is listed in Table 3.
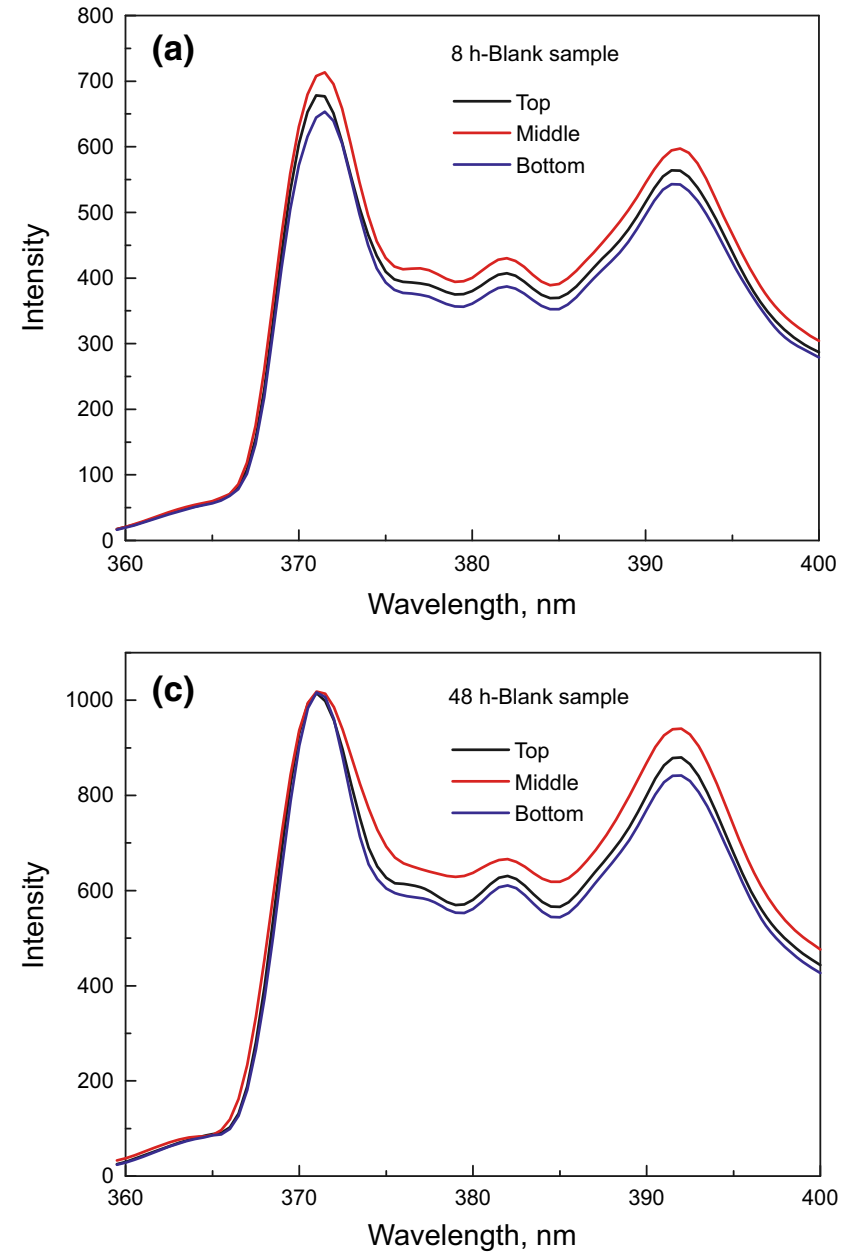

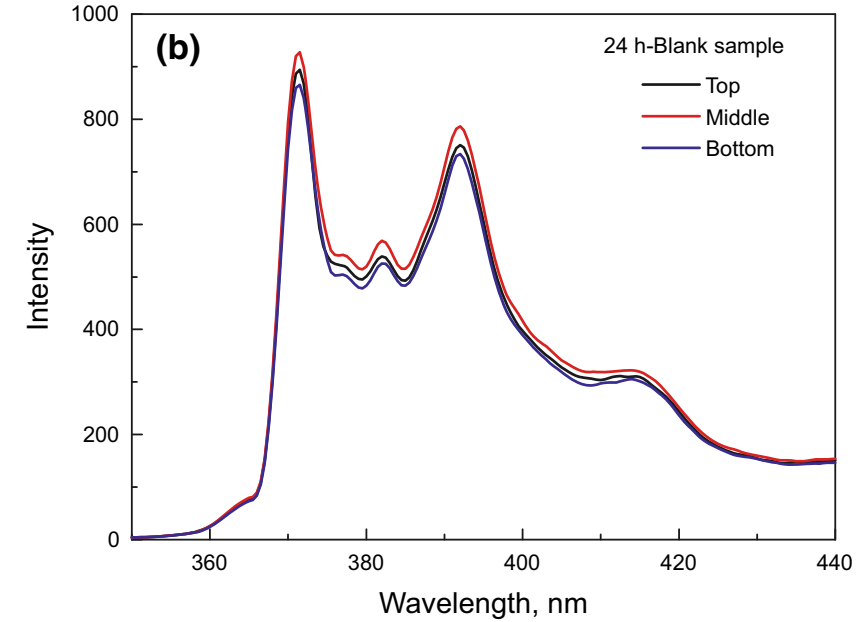

As shown in Table 3, the molecular weight of residual HMPAM was not high, but its polydispersity was high. Due to the low molecular weight and its amphiphilic property, its mobility may be similar to that of small molecular weight surfactants. There was intermolecular aggregation for residual HMPAM.

\subsection{Fluorescence spectrums}

Figure 4 shows the fluorescence spectrums of blank residual HMPAM solution at different layers and different times.

The fluorescence spectra of blank residual HMPAM solution at different layers were very close to each other at the same time. With time increasing, the fluorescence intensity increased. Table 4 lists the $I_{1} / I_{3}$ of blank residual HMPAM solution at different layers and $I_{1, t} / I_{1,0 \mathrm{~h}}$ at different times. The results showed that the $I_{1} / I_{3}$ data of blank residual HMPAM solution at different layers

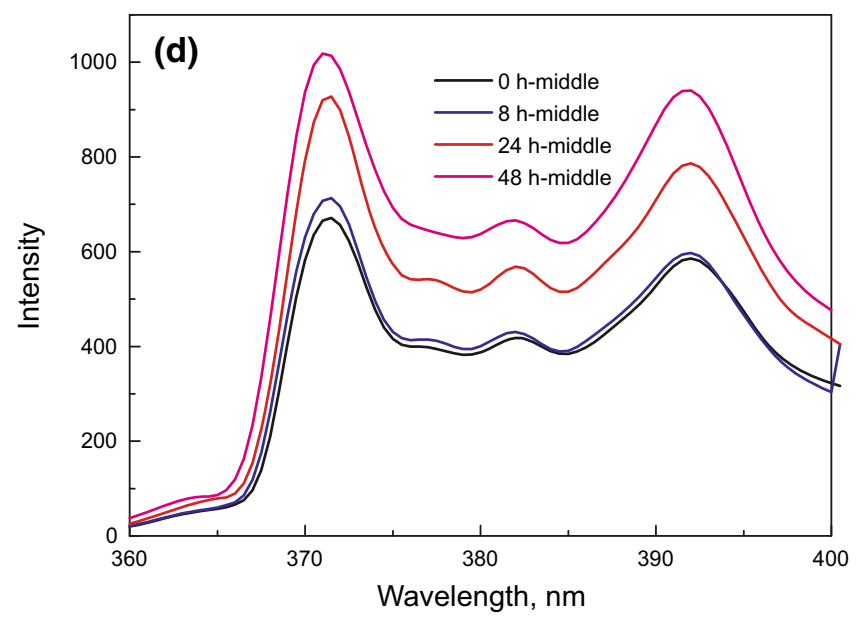

Fig. 4 Fluorescence spectra of blank residual HMPAM solution at different layers and different times 
Table $4 I_{1} / I_{3}$ of blank residual HMPAM solution at different layers and $I_{1, t} / I_{1,0 \mathrm{~h}}$ at different times

\begin{tabular}{llllcc}
\hline Layer & $I_{1} / I_{3}$ & & & Time, h & $I_{1, t} / I_{1,0 \mathrm{~h}}$ \\
\cline { 2 - 4 } & $8 \mathrm{~h}$ & $24 \mathrm{~h}$ & $48 \mathrm{~h}$ & & \\
\hline Top layer & 0.84 & 0.83 & 0.84 & 8 & 1.06 \\
Middle layer & 0.85 & 0.84 & 0.88 & 24 & 1.38 \\
Bottom layer & 0.85 & 0.83 & 0.83 & 48 & 1.52 \\
\hline
\end{tabular}

were close to each other (about 0.85 ). In addition, the $I_{1} /$ $I_{3}$ was almost not influenced by time. This phenomenon indicated that for the blank residual HMPAM solution, the polarities of hydrophobic domains formed by residual HMPAM were almost the same at different layers. Therefore, the blank residual HMPAM solution was homogeneous and the polarity of hydrophobic domains was almost unchanged over $48 \mathrm{~h}$. The increasing $I_{1, t} / I_{1,0 \mathrm{~h}}$ indicated that the number of hydrophobic domains could increase with time because the formation of hydrophobic domains is a slow process for blank residual HMPAM solution.

Table 5 shows the influence of different substances on the fluorescence spectra of residual HMPAM solution at different layers and different times.

After addition of these substances into the residual HMPAM solution, the $I_{1} / I_{3}$ of it was much larger than that of blank ones, indicating that the polarity of hydrophobic domain increased, but was not influenced by time. The increasing $I_{1} / I_{3}$ by addition of oil, suspended solids and SR bacteria may attribute to the adsorption of residual HMPAM on these substances. Because of the amphiphilic structure of the HPAM molecule due to the long alkyl chains, the adsorption of HMPAM on the oil, suspended solids and SR bacteria occurs easily. After the adsorption of HMPAM, the hydrophobic group used to form the hydrophobic domains decreased. Therefore, the polarity of the hydrophobic domains increased. The reason why $I_{1} / I_{3}$ increased after addition of $\mathrm{Fe}^{3+}, \mathrm{Fe}^{2+}$ and cationic water clarifier may be the chelation between these substances and carboxyl groups in HMPAM. After the chelation, the moving ability and rotation ability of HMPAM decreased and the hydrophobic group used to
Table 5 Influence of different factors on the fluorescence spectra of residual HMPAM solution at different layers and different times

\begin{tabular}{|c|c|c|c|c|c|}
\hline \multirow[t]{2}{*}{ Layer } & \multicolumn{3}{|l|}{$I_{1} / I_{3}$} & \multirow[t]{2}{*}{ Time, h } & \multirow[t]{2}{*}{$I_{1, t} / I_{1,0 \mathrm{~h}}$} \\
\hline & $8 \mathrm{~h}$ & $24 \mathrm{~h}$ & $48 \mathrm{~h}$ & & \\
\hline \multicolumn{6}{|c|}{ The influence of oil } \\
\hline Top layer & 1.03 & 1.02 & 1.01 & 8 & 1.15 \\
\hline Middle layer & 1.01 & 1.01 & 1.01 & 24 & 1.19 \\
\hline Bottom layer & 1.04 & 1.01 & 1.01 & 48 & 1.22 \\
\hline \multicolumn{6}{|c|}{ The influence of suspended solids } \\
\hline Top layer & 0.97 & 0.96 & 0.95 & 8 & 1.13 \\
\hline Middle layer & 0.96 & 0.96 & 0.95 & 24 & 1.37 \\
\hline Bottom layer & 0.97 & 0.96 & 0.95 & 48 & 1.62 \\
\hline \multicolumn{6}{|c|}{ The influence of $\mathrm{Fe}^{3+}$} \\
\hline Top layer & 1.17 & 1.17 & 1.18 & 8 & 1.07 \\
\hline Middle layer & 1.15 & 1.18 & 1.17 & 24 & 1.13 \\
\hline Bottom layer & 1.17 & 1.17 & 1.18 & 48 & 1.55 \\
\hline \multicolumn{6}{|c|}{ The influence of $\mathrm{Fe}^{2+}$} \\
\hline Top layer & 1.17 & 1.18 & 1.20 & 8 & 1 \\
\hline Middle layer & 1.17 & 1.19 & 1.18 & 24 & 1.40 \\
\hline Bottom layer & 1.17 & 1.19 & 1.17 & 48 & 1.89 \\
\hline \multicolumn{6}{|c|}{ The influence of cationic water clarifier } \\
\hline Top layer & 1.16 & 1.18 & 1.18 & 8 & 1 \\
\hline Middle layer & 1.16 & 1.18 & 1.20 & 24 & 1.06 \\
\hline Bottom layer & 1.16 & 1.18 & 1.20 & 48 & 1.14 \\
\hline \multicolumn{6}{|c|}{ The influence of SR bacteria } \\
\hline Top layer & 1.19 & 1.19 & 1.20 & 8 & 1.24 \\
\hline Middle layer & 1.19 & 1.20 & 1.18 & 24 & 1.43 \\
\hline Bottom layer & 1.19 & 1.20 & 1.19 & 48 & 1.50 \\
\hline
\end{tabular}

formation of hydrophobic domains decreased (see Fig. 5). Therefore, the polarity of hydrophobic domain increased.

Table 5 also showed that after addition of different substances, the $I_{1, t} / I_{1,0 \mathrm{~h}}$ increased with time. Compared to the $I_{1,48 \mathrm{~h}} / I_{1,0 \mathrm{~h}}$ of blank HMPAM solution, after addition of oil and cationic water clarifier, the $I_{1,48 \mathrm{~h}} / I_{1,0 \mathrm{~h}}$ data were much smaller. This result suggested that oil and cationic water clarifier could inhibit the increase in the hydrophobic domains. After addition of $\mathrm{Fe}^{3+}$ and SR bacteria, HMPAM solution had similar $I_{1,48 \mathrm{~h}} / I_{1,0 \mathrm{~h}}$ as the blank ones, indicating that $\mathrm{Fe}^{3+}$ and SR bacteria almost had no influence on the increase in hydrophobic domains. However, after addition 


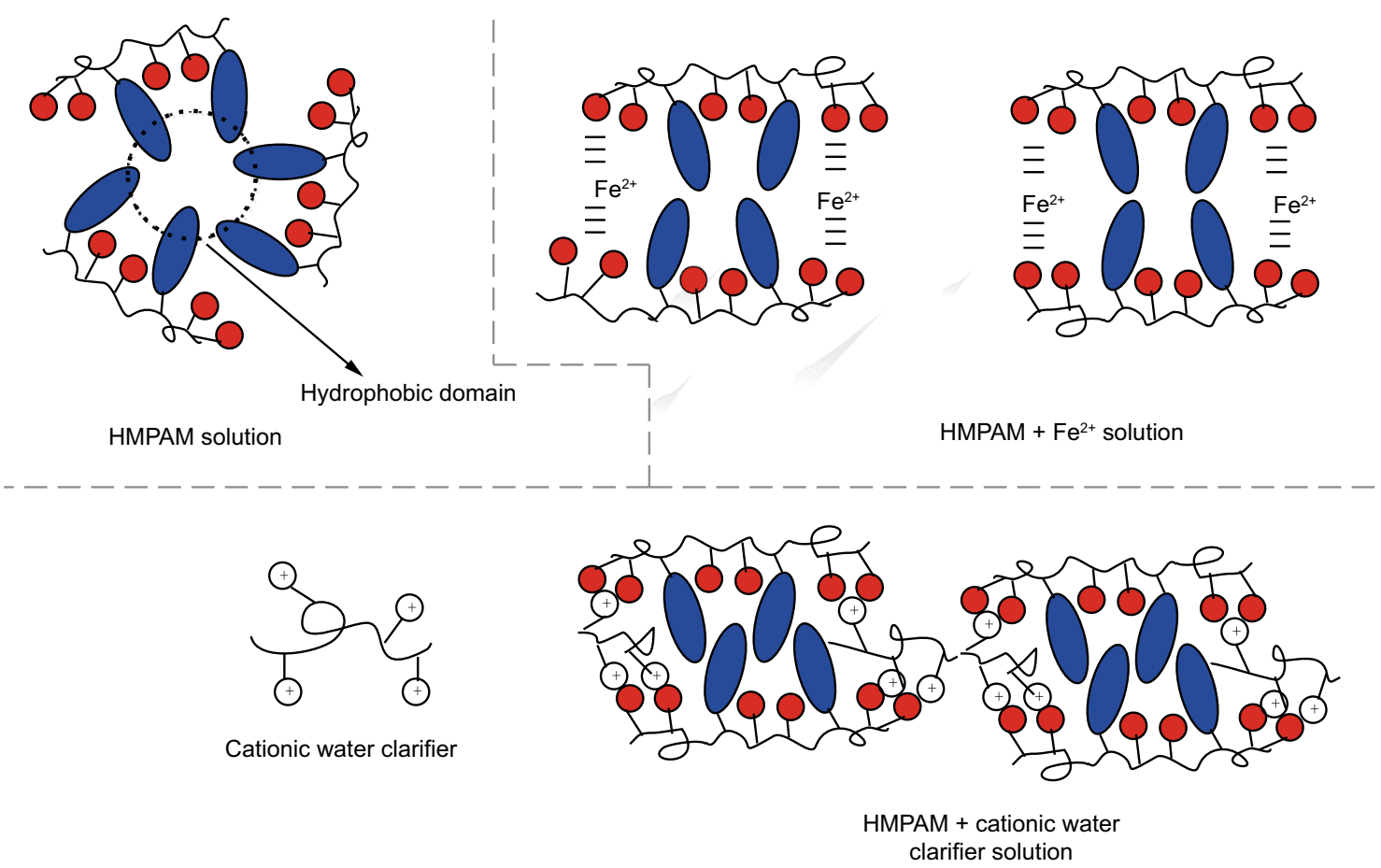

Fig. 5 Change in aggregation behavior of residual HMPAM after addition of different substances (taking $\mathrm{Fe}^{2+}$ and cationic water clarifier as example)

of $\mathrm{Fe}^{2+}$ and suspended solids, the HMPAM solution had much larger $I_{1,48 \mathrm{~h}} / I_{1,0 \mathrm{~h}}$ than blank ones, indicating that $\mathrm{Fe}^{2+}$ and suspended solids were favorable to the increase in hydrophobic domains. Usually, increasing the hydrophobic domains means an increasing degree of aggregation. In summary, with $\mathrm{Fe}^{2+}$, HMPAM solution had the largest aggregation degree $\left(I_{1,48 \mathrm{~h}} / I_{1,0 \mathrm{~h}}=1.89\right)$; with cationic water clarifier, HMPAM solution had the smallest aggregation degree $\left(I_{1,48 \mathrm{~h}} / I_{1,0 \mathrm{~h}}=1.14\right)$. After addition of $\mathrm{Fe}^{2+}$, the chelation between $\mathrm{Fe}^{2+}$ and the carboxyl groups in HMPAM would increase with time over $48 \mathrm{~h}$. Therefore, the number of hydrophobic domains increased significantly with time. Cationic water clarifier had much larger molecular weight and positive charge than $\mathrm{Fe}^{2+}$, and the electrostatic charge neutralization between cationic water clarifier and HMPAM was strong and fast. Addition of cationic water clarifier would result in larger HMPAM aggregates forming quickly. The number of hydrophobic domains would not increase with time significantly over $48 \mathrm{~h}$.

\subsection{DLS results}

Usually, the increase in the number of hydrophobic domains may be caused by an increasing number of HMPAM aggregates or increasing size of HMPAM aggregates. The results of DLS can show whether the size of HMPAM aggregates increased or not. Figure 6 shows the effects of $\mathrm{Fe}^{2+}$ and cationic water clarifier on the relationship between $R_{\mathrm{h}}$ of HMPAM and time. For blank residual HMPAM solution, the $R_{\mathrm{h}}$ had no great change with time. When $\mathrm{Fe}^{2+}$ was added in solution, the $R_{\mathrm{h}}$ also had no great change with time, indicating that the increase in $I_{1, t} /$ $I_{1,0 \mathrm{~h}}$ was caused by the increasing number of HMPAM aggregates. When cationic water clarifier was added in solution, $R_{\mathrm{h}}$ had a significant increase, suggesting that the increase in $I_{1, t} / I_{1,0 \mathrm{~h}}$ was caused by the increasing size of HMPAM aggregates.

In addition, when $\mathrm{Fe}^{2+}$ was added in solution, the $R_{\mathrm{h}}$ of it was similar to that of blank sample. But when $t$ cationic water clarifier was added in solution, the $R_{\mathrm{h}}$ of it was much 

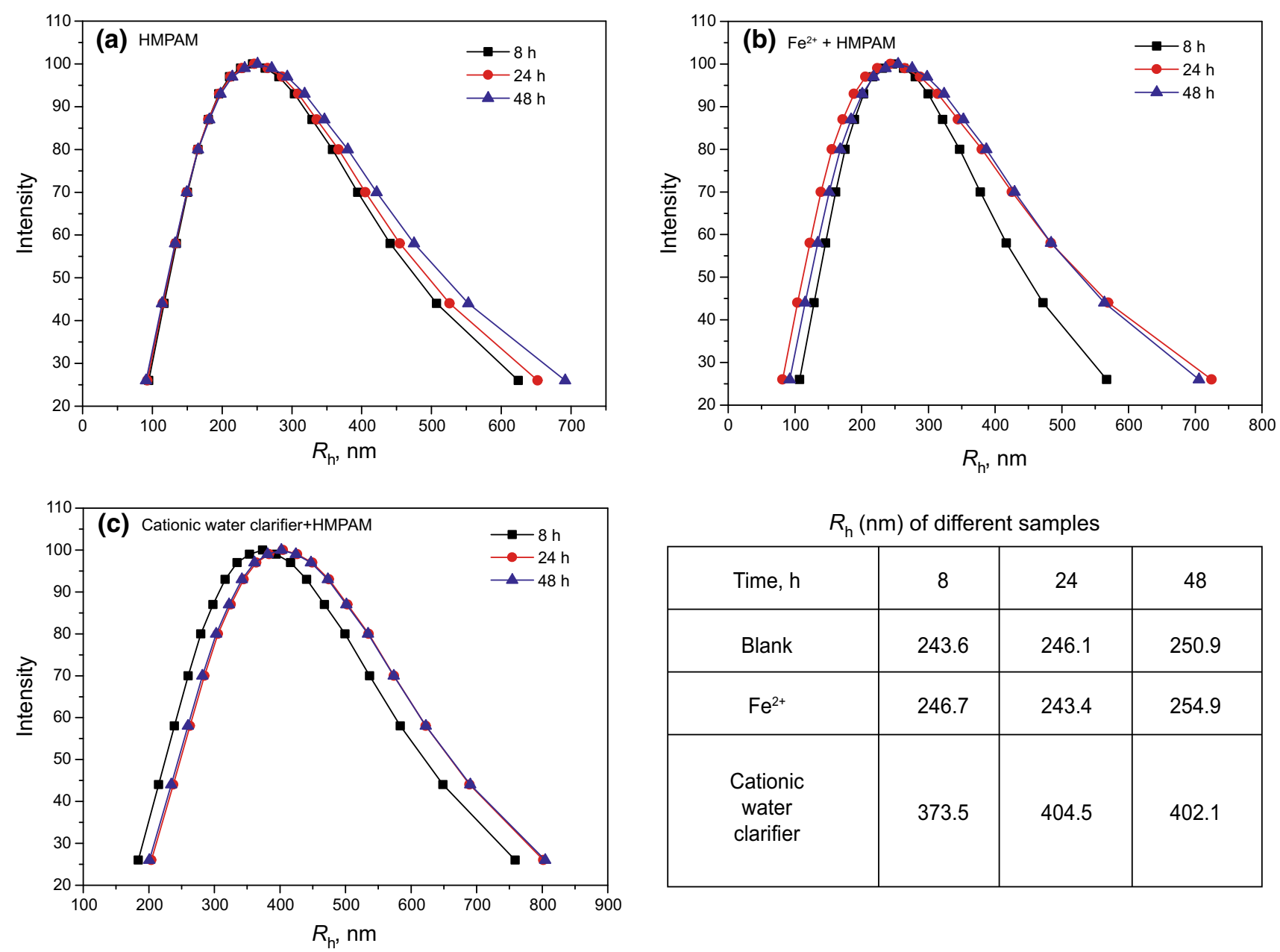

\begin{tabular}{|c|c|c|c|}
\hline \multicolumn{1}{|c|}{$R_{\mathrm{h}}(\mathrm{nm})$ of different samples } \\
\hline Time, $\mathrm{h}$ & 8 & 24 & 48 \\
\hline Blank & 243.6 & 246.1 & 250.9 \\
\hline $\mathrm{Fe}^{2+}$ & 246.7 & 243.4 & 254.9 \\
\hline $\begin{array}{c}\text { Cationic } \\
\text { water } \\
\text { clarifier }\end{array}$ & 373.5 & 404.5 & 402.1 \\
\hline
\end{tabular}

Fig. 6 Effects of $\mathrm{Fe}^{2+}$ and cationic water clarifier on the relationship between $R_{\mathrm{h}}$ of HMPAM and time

larger than that of blank ones. The results also confirmed the aggregation behavior of residual HMPAM shown in Fig. 5.

\section{Conclusion}

In this research, the influences of emulsified oil, suspended solids, $\mathrm{Fe}^{3+}, \mathrm{Fe}^{2+}$, cationic water clarifier and SR bacteria on the aggregation behavior of residual HMPAM in TOWPF were studied by fluorescence spectroscopy and DLS. After the addition of these substances into residual HMPAM solution, the $I_{1} / I_{3}$ was much larger than that of blank and not influenced by time. Oil and cationic water clarifier could inhibit the increase in hydrophobic domains. $\mathrm{Fe}^{2+}$ and suspended solids were helpful for the increase in hydrophobic domains. $\mathrm{Fe}^{3+}$ and SR bacteria had no great influence on the increase in hydrophobic domains. In summary, when there was $\mathrm{Fe}^{2+}$, HMPAM solution had the largest aggregation degree by the increasing number of HMPAM aggregates. When there was cationic water clarifier, HMPAM solution had the smallest aggregation degree because of its strong electrostatic charge neutralization with HMPAM.

Acknowledgements We acknowledge the supply of SR bacteria by Dr. Guihong Lan, who works in the School of Chemistry and Chemical Engineering, Southwest Petroleum University, in China. This work was supported by the Scientific Research Project of CNOOC (China) (Grant No. CNOOC-KJ 125 ZDXM 06 LTD NFGC 2014-01).

Open Access This article is distributed under the terms of the Creative Commons Attribution 4.0 International License (http://crea tivecommons.org/licenses/by/4.0/), which permits unrestricted use, distribution, and reproduction in any medium, provided you give appropriate credit to the original author(s) and the source, provide a link to the Creative Commons license, and indicate if changes were made. 


\section{References}

Aguiar J, Carpena P, Molina-Bolivar JA, et al. On the determination of the critical micelle concentration by the pyrene $1: 3$ ratio method. J Colloid Interface Sci. 2003;258:116-22. doi:10.1016/ S0021-9797(02)00082-6.

Fang SW, Duan M, Long WH, et al. Synthesis of copolymer of acrylamide and a cationic-nonionic bifunctional polymerizable surfactant and its micellar behavior in water. J Dispers Sci Technol. 2014;35:301-6. doi:10.1080/01932691.2013.771364.

Feng QH, Zhang G, Yin XM, et al. Numerical simulation of the blocking process of gelled particles in porous media with remaining polymers. Pet Sci. 2009;6:284-8. doi:10.1007/ s12182-009-0045-5.

Feng YJ. Study of aqueous solution structure of hydrophobically associating water-soluble polymer and its effect on the solution rheology. Ph.D., dissertation, SouthWest Petroleum University; 1999. p. 87 (in Chinese).

Gao BY, Jia YY, Zhang YQ, et al. Performance of dithiocarbamatetype flocculent in treating simulated polymer flooding produced water. J Environ Sci. 2011;23(1):37-43. doi:10.1016/S10010742(10)60370-1.

Guo AJ, Geng YR, Zhao LL, et al. Preparation of cationic polyacrylamide microsphere emulsion and its performance for permeability reduction. Pet Sci. 2014;11:408-16. doi:10.1007/ s12182-014-0355-0.

Han T, Xu GY, Chen YJ, et al. Improving performances of hydrophobically modified polyacrylamide in mineralized water by block polyether with branched structure. J Dispers Sci Technol. 2012;33:697-703. doi:10.1080/01932691.2011. 579852.

Hu GJ, Li JB, Zeng GM. Recent development in the treatment of oily sludge from petroleum industry: a review. J Hazard Mater. 2013;261:470-90. doi:10.1016/j.jhazmat.2013.07.069.

Ismail DDK. Aggregation and adsorption properties of sodium dodecyl sulfate in water-acetamide mixtures. J Colloid Interface Sci. 2008;327:198-203. doi:10.1016/j.jcis.2008.07.045.

Kim JH, Domach MM, Tilton RD. Effect of electrolytes on the pyrene solubilization capacity of dodecyl sulfate micelles. Langmuir. 2000;16:10037-43. doi:10.1021/la0005560.

Lei ZD, Yuan SY, Song J. Rheological behavior of alkali-surfactantpolymer/oil emulsion in porous media. J Cent South Univ Technol. 2008;15(s1):462-6. doi:10.1007/s11771-008-0400-5.

Li H, Ai MQ, Han SQ, et al. Microbial diversity and functionally distinct groups in produced water from the Daqing Oilfield. Pet Sci. 2012;9:469-84. doi:10.1007/s12182-012-0232-7.

Lin MQ, Xu XQ, Lv J, et al. Interfacial properties of Daqing crude oil-alkaline system. Pet Sci. 2011;8:93-8. doi:10.1007/s12182011-0120-6.

Lin MQ, Zhang CL, Zong H, et al. Influence of polymers on the stability of Gudao crude. Pet Sci. 2008;5:159-62. doi:10.1007/ s12182-008-0024-2.

Liu JX, Peng TJ, Meng KQ, et al. Kinetic behavior in self-assembly process of associative polymer solutions. J Macromol Sci A. 2016;53:215-21. doi:10.1080/10601325.2016.1143316.

Liu YG, Tang HM, Chen HX, et al. Study on produced water quality variation rule from polymer flooding and mechanism of formation damage. Offshore Oil. 2010;12:86-91. doi:10.3969/j. issn.1008-2336.2010.04.086.

Lu XG, Liu JX, Wang RJ, et al. Study of action mechanisms and properties of $\mathrm{Cr}^{3+}$ cross-linked polymer solution with high salinity. Pet Sci. 2012;9:75-81. doi:10.1007/s12182-012-0185-x.

$\mathrm{Qu}$ GH, Gong XG, Liu YK. New research progress of the demulsification of produced liquid by polymer flooding. J Chem Pharm Res. 2014;6:634-40.

Ren K, Wang JL, Lin MQ, et al. Rheological properties of hydrophobically associating polyacrylamide solution. Pet Sci. 2006;3(2):66-72.

Shen PP, Song J, Zhu B. Improved oil recovery technology in China: status and outlook. China Oil Gas. 2005;12:6-9.

Shi LT, Chen L, Ye ZB, et al. Effect of polymer solution structure on displacement efficiency. Pet Sci. 2012;9:230-5. doi:10.1007/ s12182-012-0203-Z.

Shi LT, Chen L, Ye ZB, Zhang Z, et al. Necessity and feasibility of improving the residual resistance factor of polymer flooding in heavy oil reservoirs. Pet Sci. 2010;7:251-6. doi:10.1007/s12182010-0029-5.

Tuncal T, Uslu O. A review of dehydration of various industrial sludges. Dry Technol. 2014;32:1642-54. doi:10.1080/07373937. 2014.909846.

Wever DAZ, Picchioni F, Broekhuis AA. Polymers for enhanced oil recovery: a paradigm for structure-property relationship in aqueous solution. Prog Polym Sci. 2011;36:1558-628. doi:10. 1016/j.progpolymsci.2011.05.006.

$\mathrm{Xu}$ ZS, Zhang JH, Feng ZH, et al. Characteristics of remaining oil viscosity in water- and polymer-flooding reservoirs in Daqing Oilfield. Sci China Earth Sci. 2010;53(1):72-83. doi:10.1007/ s11430-009-0184-y.

Yang J, Li JY, Pan LL, et al. A study of properties of dilute polymer systems prepared with polymer-bearing wastewater. Appl Mech Mater. 2014;464:31-6. doi:10.4028/www.scientific.net/AMM. 464.31 .

Zhang J, Jing B, Fang SW, et al. Synthesis and performances for treating oily wastewater produced from polymer flooding of new demulsifiers based on polyoxyalkylated $N, N$-dimethylethanolamine. Polym Adv Technol. 2015a;26:190-7. doi:10.1002/pat. 3433.

Zhang J, Jing B, Tan GR, et al. Effect of structure of graft on the properties of graft copolymers of acrylamide and surfactant macromonomers dilute aqueous solutions. J Macromol Sci Phys. 2015b;54:253-61. doi:10.1080/00222348.2014.1000798.

Zhang LJ, Yue XA, Guo F. Micro-mechanisms of residual oil mobilization by viscoelastic fluids. Pet Sci. 2008;5:56-61. doi:10.1007/s12182-008-0009-1.

Zhang LJ, Yue XA. Displacement of polymer solution on residual oil trapped in dead ends. J Cent South Univ Technol. 2008;5:84-7. doi:10.1007/s11771-008-0320-4.

Zhao YZ, Zhou JZ, Xu XH, et al. Synthesis and characterization of a series of modified polyacrylamide. Colloid Polym Sci. 2009;287:237-41. doi:10.1080/10601325.2016.1143316.

Zhong CR, Luo PY, Meng XH. Aggregation behavior of a watersoluble terpolymer with vinyl biphenyl characterized by a fluorescent probe. J Appl Polym Sci. 2010;116:404-12. doi:10. 1002/app.31071. 